\title{
For the many: a curriculum for social justice
}

The Labour Party's consultation document 'Towards a National Education Service' (2018) is liberating in two major ways. Firstly it goes beyond the neoliberal emphasis on education as the production of human capital by regarding the purpose of learning as 'to succeed not just in the world of work but in their own development'. Secondly it promises to extend the opportunity to learn 'to everyone, at any time in their life, regardless of their circumstance or background'.

Some of the mechanisms to achieve this are already in policy since the 2017 General Election, such as bringing back the Education Maintenance Allowance and university maintenance grants, and scrapping university tuition fees. However there is a lack of clarity when it comes to the substance of learning.

Two of the document's Key Principles touch on this:

1) Education has intrinsic value in giving all people access to the common body of knowledge we share, and practical value in allowing all to participate fully in our society.

6) All areas of skill and learning deserve respect; the National Education Service will provide all forms of education, integrating academic, technical and other forms of learning within and outside of educational institutions, and treating all with equal respect.

The importance of access to knowledge, and equal respect for all kinds of skill and learning, are an important educational and democratic starting point, but too broad to give much sense of direction. Indeed, the former could have been used by Michael Gove to justify his ultra-standardised 'knowledge-based' National Curriculum, while the latter sentiment has already been used to justify New Labour's secondary curriculum after the 2006 Act which, in effect, divided young people from age 14 into academics and vocationals.

The history of the school curriculum in recent decades (see Wrigley 2014 for detailed discussion) can be written in terms of an oscillation between two opposing (and complementary) tendencies:

i) the universal imposition of a standardised National Curriculum based on archaic lists of content and performance norms originating in elite schools - education for the many, designed for the few; ii) the premise that, because this has failed, around half our young people should be levered into a parallel curriculum providing early training for (mainly low skill, low paid) work.

It is difficult to recognise either as a socialist position.

This article aims to review the recent history of both of these options, and then tentatively explore some key principles for curricular justice. 


\section{A debased version of traditional elite learning}

Since the start of universal schooling in the 1870s, it has been normal to constrain schooling for 'the masses' to those elementary literacy and numeracy skills known as the 3Rs, complemented by socialisation as obedient workers and pride in Empire. The Payment By Results system guaranteed a particular version of quality; inspectors visited to monitor children's achievement in reading aloud, neat handwriting, correct spelling and mental arithmetic. There was no policy ambition beyond the efficient transmission of a limited skills set, with quality defined in terms of accuracy in reproductive tasks.

Many teachers resisted such narrowness, and resistance was a core principle of the National Union of Elementary Teachers, founded in 1870 and which later became the NUT. Many teachers sought to introduce children to history, geography and science through 'object lessons', though the ideological control steered history and geography towards state-approved ends, with an emphasis on national glory and the global reach of Britain's imperial possessions.

Despite subsequent changes including free grammar school places for a small proportion of working-class pupils, the vast majority endured a constrained curriculum until late in the 20th Century. Although superficially the coverage and division into subjects was quite similar to that of grammar schools, though with rather more room for practical learning such as cooking and woodwork, this was 'knowledge' only in a very limited sense, as memorisation rather than problemsolving, interpretation or cognitive development.

Some bold attempts were made to transcend these limitations, including the growth of progressive primary methods culminating in the Plowden Report, new approaches to the subject English around the 1970s, and the many Schools Council curriculum projects which aimed to make thoughtful and challenging learning accessible to the majority (Wrigley 2014:10-13) All of these were beaten back when the Thatcherite counter-revolution began to target education. The National Curriculum notionally established a broad entitlement for all young people, but the pressures of accountability (SATs, Ofsted, and later performance pay and threatened academisation) ensured that the real curriculum in poorer locations focused on a more limited range of knowledge and skills.

The mechanism whereby the National Curriculum was formulated involved subject committees consisting of around ten experts; most of them were not educators and those who were tended to be selected from elite schools. The main approach was to define and sequence mandated content rather than considering how to expand the horizons and capacities of young people by building on their personal experience, vernacular community-derived knowledge and local contexts of work and social history. 


\section{A selection from the culture}

Proponents of the official approach had to suppress the understanding that the school curriculum is necessarily only a selection from available knowledge, and furthermore a selection by, or in the interests of, a social elite. Raymond Williams (1961:66seq) had pointed out that the curriculum can only ever be a selection from the wider culture and that the apparently stable and authoritative 'tradition' or 'canon' was in fact a 'selective tradition'. His own work on English literature challenged not only the content - the list of worthy texts - but also the ways in which we are expected to study them and the questions which it is legitimate to ask. By stepping outside these parameters and relating literary texts to history and culture, Williams noticed structural features which more conservative readings had missed. For example:

Neighbours in Jane Austen are not the people actually living nearby; they are the people living a little less nearby who, in social recognition, can be visited. What she sees across the land is a network of propertied houses and families, and... most actual people are simply not seen. To be face-to-face in this world is already to belong to a class. (Williams 1985:166)

The curriculum often omits and excludes in socially prejudiced ways, as Bertold Brecht succinctly points out in his comment on how history is often presented to young people:

\section{Questions from a Worker who Reads}

... Caesar beat the Gauls.

Did he not even have a cook with him?

Philip of Spain wept when his armada sank.

Was he the only one to cry? (Brecht 1935)

This understanding transferred to sections of the teaching profession. Prior to the National Curriculum, history teachers began to engage with local working-class history, as well as adapting the interpretative skills of university history into school school. English teachers built bridges between books written for adolescents and literary texts, and used autobiographical writing as a stepping stone towards more formal genres. Even when the National Curriculum mandated the study of Shakespeare for all students from age 13, some teachers responded by fostering real engagement through dramatic readings and improvisations, and emphasised the connectedness of key social themes with issues in young people's own lives rather than adulate the iconic author.

\section{Hygiene and nostalgia}

An important aspect of neo-Conservative traditionalism was a belief in cultural tidiness, and the need to impose order on potentially messy working-class lives. Conventions of syntax, spelling and punctuation were ascribed quasi-magic powers in washing clean the disorderly characters of 
working-class children. Deputy prime minister Norman Tebbit once protested that the neglect of grammar teaching had contributed to a breakdown in law and order:

If you allow standards to slip to the stage where good English is no better than bad English, where people can turn up filthy and nobody takes any notice of them at school - just as well as turning up clean - all those things tend to cause people to have no standards at all, and once you lose your standards then there's no imperative to stay out of crime. (Tebbit 1985)

In the Tory imagination, grammar came to signify both accurate Standard English and the lamented grammar schools, while standards merged academic performance with public order.

This combined with a nostalgia for the imamgined former glories of the grammar school, and derision of comprehensive schools as a supposed hotbed of ideological revolt. A 'discourse of derision' was in crescendo. In 1987, Margaret Thatcher informed her party conference:

Children who need to count and multiply are being taught antiracist Mathematics, whatever that may be. Children who need to be able to express themselves in clear English are being taught political slogans. Children who need to be taught to respect traditional moral values are being taught that they have an inalienable right to be gay.

The implicit expectation was for education to be purged of politics and alternative thinking, indeed of all connectedness to working-class lives. History was an inevitable target. Repeated calls were made to remove critical interpretation: school history should be concerned with 'the transmission of an established view of the past'. Education minister Kenneth Clarke (1991) issued his notorious decree that school history should stop 20 years before the present day. Indeed, no space was allowed in the National Curriculum for any study of contemporary society.

\section{The core and the margins}

The National Curriculum privileged English, Mathematics and Science (subsequently, in effect, joined by ICT) as 'core subjects'. The imbalance worsened in Gove's revision; a page count is sufficient to establish that overwhelming emphasis is given to just two and a half subjects: Maths, Science and the literacy component of English. This neglect of spoken English at Key Stages 1 and 2 was reinforced by its removal from English Language GCSE. Ofsted had already chosen to focus almost exclusively on literacy and numeracy, to the extent that half of primary school inspection reports in the first half of 2016 did not even mention Science (Wellcome Trust 2016). Other subjects were often sacrificed, especially in Year 6, as extreme accountability pressures led to test preparation swallowing more and more time. In early education, there have been similar pressures to focus on early indicators of literacy and numeracy, rather than spoken language, play and discovery (Ofsted 2017). 
Gove's invention of the EBacc has led to an increasing neglect of creative and practical subjects. The Progress 8 measure has moderated this slightly, since it allows some space for non-Ebacc subjects. Nevertheless, the overall trend has been for fewer and fewer students to study art, drama, music and CDT.

This is particularly critical given the contribution these subjects make to creativity, the scope they offer to young people's initiative, and the satisfaction derived from working towards a product or performance which can be appreciated by parents and peers.

\section{Too much too young}

The neoliberal insistence on education overwhelmingly servicing economic production by producing 'human capital' (Ball 2008) has fuelled an intensification of learning and the imposition of unrealistic targets on younger and younger children. Rather than improving quality, it has led to greater superficiality. The spaces for more expansive and thoughtful learning have been taken over by the secretarial aspects of literacy, the explicit teaching of grammatical terminology, and rapid and accurate performance of arithmetic algorithms.

This was entirely predicted by the 'Too Much Too Young' open letter from 100 academics:

The proposed curriculum consists of endless lists of spellings, facts and rules. This mountain of data will not develop children's ability to think, including problem-solving, critical understanding and creativity.

Much of it demands too much too young. This will put pressure on teachers to rely on rote learning without understanding. Inappropriate demands will lead to failure and demoralisation.

The learner is largely ignored. Little account is taken of children's potential interests and capacities, or that young children need to relate abstract ideas to their experience, lives and activity. (Hundred Academics, 2013)

What we did not foresee was the massive emotional stress this would place on children as well as teachers. Repeatedly the government and DfE have failed to attend to the small matter of child development - the very notion that children take time to grow intellectually and emotionally as well as physically seems anathema.

\section{Inbuilt failure}

The escalation of demands on children, combined with a disregard of child development issues and high-stakes accountability mechanisms, leads inexorably to high numbers of children being declared failures. We have reached the point where around half of children are moving on to 
secondary school with a failure notice around their necks. Of those labeled 'disadvantaged' (i.e. who have been entitled to free school meals at any time in the past six years), nearly two thirds are failed in reading, writing or mathematics in SATs at age 11 (More Than A Score 2017:11).

The height of the hurdles is being raised at every juncture, whether GCSE and A-levels or unrealistic academic requirements for selection into relatively low-level work. The paradox of raised levels of difficulty combined with increasing economic divisions undermines the ideology of 'social mobility' whilst giving young people the impression that they are responsible for their own precarity. As Michael Rosen suggested with considerable foresight:

Capitalism can no longer see a way to employ all the clever well qualified people. In their terms, schools are producing too many students at 18 who are performing well enough to go to university and do a degree, so barriers are put in their way. Exams must be made harder, grants are taken away and fees charged, universities must shed so-called useless courses. (Rosen 2012)

\section{Some conclusions}

This section has deconstructed some of the rhetoric behind universalistic, standardising policies which supposedly unify the population and raise the general quality of lives. It has opened to question naive suppositions that the curricular canon is simply 'common sense', self-evidently correct and appropriate to all social groups. It has unsettled the curricular hierarchies whereby some forms of knowledge is worthier than others. It has probed the claims that the escalation of difficulty and accountability targets will result in a more equal, or even a more prosperous, future for the population.

Despite its advocates claims, a standardised curriculum, premised on 'high academic standards', is having a harmful impact on educational levels, while damaging mental health, making social mobility less likely and leading to superficial and short-term gains in 'knowledge' which might be lacking in understanding.

\section{Academics and vocationals}

There is a longstanding notion that academic and vocational studies constitute a binary, are mutually exclusive, and the latter is inferior to the former. All of this is problematic.

One underlying assumption is that academic studies are theoretical and vocational practical. This is based on the premise that abstract theory is necessarily decontextualised or unsituated. It fails to recognise the dynamics between situated experiences and constructing theory, a dialectic in which we step back from our experiences in order to understand the patterns and forces at work, aided by concepts which might have been transferred from other situations. 
Conversely, vocational learning is assumed to be unthinking, crudely material - an aristocratic prejudice. Not only does it discount highly theorised professions such as medicine, architecture or engineering, it underestimates the intelligent diagnosis, material knowledge, and creative problem solving involved in plumbing or gardening. As used in this way, vocational is not a neutral term denoting preparation for employment but suggests work of a less exalted and more routine kind. The prejudice has a long history in English education. The Norwood Committee (Board of Education 1943), in its design for a post-war tripartite system of secondary education, described the potential pupils of grammar, technical and 'modern' schools as:

- the pupil who is interested in learning for its own sake

- the pupil whose interests and abilities lie markedly in the field of applied science or applied art - [the pupil who] deals more easily with concrete things than with ideas.

The grammar school pupil is optimistically imagined as an idealistic and disinterested scholar; skilled occupations are seen as inferior; and the lowest level, for the majority, is regarded as devoid of ideas.

The development of comprehensive schools involved not only the unification of pupils in a single building, but a direct challenge to curricula based on such divisive premises. Critically when the school leaving age was eventually raised to 16 , new ways of teaching maths and history had to be developed which grounded ideas in practice, and new hybrid courses developed which built analysis and creativity on the vernacular experiences of working-class students.

This was seriously jeopardised by New Labour's Education and Inspection Act of 2006, which reintroduced a radical divide at age 14 . For the 'more academic' student, most of whom were destined for university, there was a reiteration of the 1980s 'broad and balanced' curriculum, including the entitlement to a social subject (history or geography), creative arts (now including media), a language, and a branch of design and technology. For the 'less academic', all these entitlements were jettisoned and replaced by an extended vocational course. This was a decidedly neoliberal reform, though reconciled with traditionalist views of a natural hierarchy of talents. There was nothing new in 14-16 year olds following a vocational course, often in a nearby college, as part of a broad curriculum. In the school where I taught in the early 1970s, large numbers of 1416 year olds studied childcare and car mechanics on site, or bricklaying and hairdressing at the local college, and nobody suggested that these same pupils should not also choose drama, geography or a language. 
After 2006, pupils were required to make firm decisions to embark on specific vocational courses from age 14, narrowing their future pathways. Even English and maths could be replaced by functional literacy and numeracy. Ironically the careers to which these were supposed to lead were becoming increasingly elusive.

This notion of a population divided into two - the academics and the vocationals - was unfortunately carried forward into later Labour Party manifestos. It is not inevitable, or universal. Indeed, in most European countries, there is a broad and balanced curriculum with little subject choice to age 16 , and division into academic and vocational specialisms begins at 16 . In some the options remain open even longer: for example in Norway, vocational courses from 16 include a strong element (roughly a third) of language, maths, science, sport and citizenship, and crossover to pre-university courses is common after two years.

\section{"Knowledge'}

The invocation of 'knowledge' has seriously distorted curriculum formation in recent years. In England it was used by Gove and his traditionalist allies to construct and justify a curriculum which was abstract and disconnected from many students' lives, and which has led to massive failure rates. The intellectual origins can be found in E D Hirsch's 'cultural literacy' project and in a group assembled round Michael Young and calling themselves Social Realists.

Like other feelgood terms (leadership, school effectiveness, accountability, evidence etc) the positive accentuation of 'knowledge' makes it difficult to resist. However, because such words produce ideological effects because they seem self-evidently correct, it is all the more important to interrogate them.

Hirsch has argued that it is the lack of factual knowledge across a wide range of cultural phenomena and intellectual domains that consign lower class students to educational failure: they simply don't have the reference points to understand key texts. His answer has been to compile comprehensive lists of essential knowledge, most of them presented as fragmented facts. Let us consider this extract taken from Grade 4 (approx. Y5) of the US version (Core Knowledge Foundation 2013):

\section{The Inca:}

- ruled an empire stretching along the Pacific coast of South America

- built great cities (Machu Picchu, Cuzco) high in the Andes, connected by a system of roads Spanish Conquerors:

Conquistadors: Cortés and Pizzaro

- Advantage of Spanish weapons (guns, cannons) 
- Diseases devastate native peoples

The obvious danger, given the massive lists of essential facts, is that will be treated as a memorisation exercise in most schools, and learning will be superficial. It is difficult to see how acquisition of these details could support longer term intellectual or social development. Hirsch has repeatedly been accused of an Anglo- or Eurocentric selection. Here we see something worse: these 'facts' strip indigenous cultures to a few physical markers, whilst obscuring the vicious cruelty of the conquest. Imperial history is reduced to a list of neutral facts: slavery (Cuba, Puerto Rico, Bahamas, Dominican Republic, Haiti, Jamaica). The Reformation is summed up as 'Martin Luther and the 20 Theses; John Calvin. This endless drizzle of inert facts is merely the shadow of knowledge, crumbs falling off the table of high culture. While pupils in advantaged schools will learn the trombone, the rustbelt kids will label a picture on a worksheet.

The list is endless, but we are all too familiar with this approach in Gove's National Curriculum reform with its interminable lists of spellings and grammatical terms. Many will also remember the primary history curriculum which hit the rocks. As Simon Schama (2013) pointed out, the amount of content would make it impossible to engage learners seriously:

vroom, there was Disraeli, - vroom - there was Gladstone... the French Revolution, maybe if it's lucky, gets a drive-by ten minutes at this rate.

He described as 'Gradgrindian' cramming children with so many facts, and ridiculed the arbitrary selection of detail:

There are no key-developments in the reign of Aethelstan, because it's stupid really. In a recent conference presentation, schools minister Nick Gibb quotes Hirsch:

Those children who possess the intellectual capital when they first arrive at school have the mental scaffolding and Velcro to gain still more knowledge. (Gibb 2015)

Whilst there is some truth in the claim that subject-specific knowledge provides an essential scaffold for developing understanding, the Cultural Literacy lists of 'core knowledge' place too much emphasis on factual detail, and not enough on concepts and explanations. Perhaps 10 or 15 key dates are sufficient for a general chronological framework of British history, whilst memorising 100-150 simply produces a blur. Isn't something rather more substantial needed as a framework for knowledge building than a list of dry facts.

Gibbs lampoons the 2007 version of the National Curriculum as neglecting knowledge, and it is true that a broad outline of content would have been useful for coherence at each Key Stage. However he reveals his own simplicity and superficiality. He attacks, for example, secondary 
school Geography for focusing upon 'concepts' such as 'physical and human processes' and 'cultural understanding and diversity'. In fact, these are simply the subheadings for groups of concepts: the concepts themselves include:

- Understanding how sequences of events and activities in the physical and human worlds lead to change in places, landscapes and societies.

- Appreciating how people's values and attitudes differ and may influence social, environmental, economy and political issues, and developing their own values and attitudes about such issues.

What is being attacked here is the learners' sense of their place in the world, critical understanding, environmental and social responsibility, ethical awareness, a sense of change - and with all this, knowledge as engagement with the world. The irony being that all this is being marginalised in the name of Knowledge.

The Social Realist stance is more subtle. Reacting - quite understandably - to the technical instrumentalism running through neoliberal curricululm policy, including the substitution of lowlevel vocational skills for cognitive knowledge, Young and his allies argued that theoretical understanding rooted in traditional academic disciplines was vital. The insistence on theory, and the need to go beyond simple experience, is well founded. As Marx pointed out:

All science would be superfluous if the outward appearance and the essence of things directly coincided. (Marx 1894, ch48)

However, Young and colleagues somehow reached the conclusion that the road to a high quality education for all was the divorce of curricular knowledge from everyday experience.

It is important that the pupils do not confuse the Auckland that the geography teacher talks about with the Auckland in which they live. To a certain extent, it is the same city, but the pupil's relationship with it in the two cases is not the same. The Auckland where they live is 'a place of experience'. Auckland as an example of a city is 'an object of thought' or a 'concept'... For example, the teacher might ask her class what the functions of the city of Auckland are. This requires that the pupils think of the city in its role in government and business and not to just describe how they, their parents, and their friends, experience living in the city. (Young 2010:25-6)

This is extremely revealing. Instead of using concepts to shed light on the cities of our everyday experience, in order to understand the forces which shape our lives, the Social Realists' call is for abstract concepts to replace rich experience. 
Margaret Roberts (2014:197) countered this by pointing out thaat the key characteristics of cities cannot be reduced to universalistic generalisations: they are highly contextualised.

This was not a random mistake on the part of the social realists: Young reiterates the argument on numerous occasions.

If education is to be emancipatory... it has to be based on a break with experience. (Young et al 2014:88)

The curriculum should exclude the everyday knowledge of students (ibid:97, my italics) Young's concession that experiences could be used as a pedagogical device to interest students in academic subject matter is insufficient. There are many valuable examples of curriculum which build on students' everyday lives and concerns, which develops a considered and theory-informed understanding out of key personal and social issues. Nel Noddings' book Critical lessons (2006) shows how an intellectually challenging and socially critical curriculum can be built from themes such as parenting, making a living, advertising and propaganda, other people, and the psychology of war. Eric 'Rico' Gutstein's mathematics teaching in Chicago applies maths to young people's concerns about housing (Gutstein 2012). In such 'citizenship mathematics', the focus on housing is not just than a pedagogical hook, a motivating illustration ancillary to the main purpose of teaching a corpus of mathematical skills and knowledge. Housing is important in its own right: the curriculum is both mathematics and citizenship, each strengthening and mediating the other.

To insist on a separation between concepts and experience is to reinforce:

standard educational processes whereby working-class culture is excluded and misrecognized, where Indigenous knowledges are denied, where cultural differences are elided and only professional and higher class cultures and knowledges are ratified and become cultural, social and symbolic capital that advantages some and disadvantages others. (Wrigley et al 2012:99)

Underlying this is a reified view of knowledge which sees it as a collection of facts, rather than as a reaching out from the learner to the world mediated by significant examples and powerful concepts. This turns learning into alienated labour where the student is not engaging intellectually and intelligently with the world but 'banking' knowledge (Freire 1970) in order to pass exams and gain credentials.

Furthermore, it relies on a misunderstanding of mind as a space inside the head, rather than as situated and stretching out between social beings and the natural or social world. Running through Gove's National Curriculum is an exaggerated view of the importance of rules - a deeply 
conservative mistake - and a misunderstanding of the relationship between symbols and activity.

Gilbert Ryle challenged such a view in The Concept of Mind, according to which:

The chef must recite his recipes to himself before he can cook according to them; the hero must lend his inner ear to some appropriate moral imperative before swimming out to save the drowning man; the chess-player must run over in his head all the relevant rules and tactical maxims of the game before he can make correct and skilful moves... Certainly we often do not only reflect before we act but reflect in order to act properly. The chess-player may require some time in which to plan his moves before he makes them. Yet the general assertion that all intelligent performance requires to be prefaced by the consideration of appropriate propositions rings unplausibly... Efficient practice precedes the theory of it. (Ryle 1949:31-2)

The error takes various forms in the Gove curriculum: children expected to spell words which are not in their vocabulary (eg merriment, quantity in Year 2, interrelated and outrageous in Year 3); learn endless rules which require a complex logic to apply ('If the root word ends with -ic, -ally is added rather than just -ly except in the word publicly.'); the whole business of Synthetic Phonics. In Mike Rosen's analogy:

We at Ruth Miskin Academy are pioneering Miskin Kick Score Incorporated where in the first year you play Un-Football, by playing without the ball. (Rosen 2012)

This invocation of 'knowledge' as abstract, decontextualised, fragmented, bleached of ethical and aesthetic resonance, is by no means 'powerful knowledge' (the social realistic keyword), either in helping us understand the natural world or in gaining a critical understanding of the social world.

\section{What might a socially just curriculum look like?}

It is beyond the scope of this article to give a shape to a future curriculum. This final section will, however, outline some considerations which will give clarity to the rather vague 'key principles' found in 'Towards a national education service'.

\section{A breadth of human purpose}

Whilst creating a skillled and knowledgeable workforce is vital to the regeneration of the economy, this is not its only purpose. Learning, for all ages, is important for personal development, healthy living, culture in the broadest sense, the development of respectful and just social relationships, to care for the environment, and for democratic citizenship nationally and internationally. This breadth should be reflected in the school curriculum, but also for young people pursuing technical and vocational specialisms in colleges and universities, and in community education. 


\section{Broad and balanced}

Policy in recent years has led to narrowing of curricula at various points. The recent paper Bold Beginnings (Ofsted 2017) places excessive emphasis on literacy and numeracy, marginalising play, spoken language, co-operation, self direction, and so on. Public spending on adult education has been limited to courses of vocational relevance, even damaging TESOL. It should be a touchstone of the National Education Service that adult learners are entitled to pursue their interests whether for leisure, heritage, citizenship, culture or work.

Whatever the scope for negotiation and choice, all young people to age 16 should have a broad and balanced curriculum including understanding the natural world (science), understanding society and the environment (history, geography, elements of social sciences), creative and performing arts (including media), and technical / vocational studies. We also need discussion about how to keep open the post-16 curriculum beyond three A-levels or a vocational specialism.

\section{Related to the age, interests and concerns of the learner}

The pressure placed on children under 7 to meet premature targets of literacy and numeracy should be removed, recognising that children develop at different speeds and with varying strengths and that young children need a relatively informal learning environment with time for various kinds of play, construction, talk and interaction. Throughout the school years, we should keep open some space for learners to pursue their own enquiries and activities. At no stage should education be dominated by a one-way transmission of knowledge or memorisation for closed-paper exams.

\section{Head, heart and hands}

The EBacc represents a particularly strong version of the marginalisation of practical, ethical and aesthetic dimensions of learning and the dominance of the abstract. A better balance needs to be achieved between these and the cognitive dimension. The development of young people is more rounded and authentic when cognitive development is rooted in experience and activity.

Such environments produce high-quality cognitive developmemnt, education for citizenship, and authentic engagement and motivation - knowledge that is more than a drizzle of inert facts and mind-numbing worksheets. They produce learning which is simultaneously grounded and critical. (Wrigley, Thomson and Lingard 2012:197)

\section{Respecting community knowledge}

Where possible, the curriculum should link initiation into high-status knowledge with respect for, and engagement with, the knowledge and cultural activities of local or minority ethnic 
communities. This might involve extension of cultural learning to include popular traditions, communication in a range of community languages / dialects or media, or the application of maths and science to local concerns. We should recognise that formal communication in standard English is not helped by destroying people's confident use of more familiar language, based on the prejudice that other forms of language need to be 'cured, cleansed, pursed of deformities rather than extended, enriched, developed.' (Harold Rosen 1981:75). An openness to learners' own speech is about respect, and is a precondition for enabling them to become articulate participants and active citizens.

The great advances made in the teaching of English by Harold Rosen and his contemporaries involved:

affirming the worth of the ordinary experience of working-class children and signifying it through improvised drama, classroom discussion and literary and argumentative writing. (Medway and Kingwell 2010:764)

English became a space in the curriculum which the lives of working-class students, their families and communities, were allowed to enter. But although the curriculum began in the local streets, it didn't end there, as a naive celebration of the here and now. It was a curriculum subject where students' critical and creative capacities were strongly developed. There is no contradiction between rootedness and opening horizons.

The search for 'relevance' is not in itself sufficient, nor is the proposal that learning be made more 'experiential', as both can mean an uncritical assimilation to the status quo. We prefer 'connectedness' to 'relevance' because it indicates both a respect for students' knowledges and interests and the need to scaffold learners into other knowledge forms, genres and media from which disadvantaged students should never be excluded. Wrigley, Thomson and Lingard (2012:197)

\section{Voice and agency}

Learning is often alienated labour: you are told what to do, how long to do it for, then given a mark or grade as an extrinsic reward. Authentic learning, however, involves the student's voice and agency. The curriculum should be open enough for students, with their teacher's guidance, to design experiments, solve problems or express their thoughts and feelings.

Problem solving, creative expression and initiative are not optional extras: they are intrinsic to a curriculum for social justice and democratic citizenship. 
The recent history of imposed curriculum change has shown the damage of divorcing curricular knowledge from skills, from experience, from the everyday. Knowledge is powerful, but not as Hirsch and Young conceive it. Education for liberation involves really powerful knowledge. This doesn't separate official learning from real-life concerns: it puts them into dialectical relationship, using theory to shed light on everyday situations and using the standpoints of students' social experience to look at traditional knowledge in new ways. Our position in the world gives us new ways of 'reading the word' (Freire) whilst reading the word provides us with more powerful tools for understanding and acting in the world.

\section{References}

Ball, S (2008) The education debate. Bristol: Policy Press

Board of Education (1943; 1962 edition) Curriculum and examinations in secondary schools, page 139, cited in Lawson and Silver (1973) p422

Brecht, B (1935) Questions from a worker who reads (trans. M Hamburger). In Bertolt Brecht (1976) Poems 1913-1956. London: Methuen

Clarke, K (1991) Announcement on history teaching in schools. Daily Telegraph, 14 Jan 1991

Core Knowledge Foundation (2013) Core knowledge sequence: content and skill guidelines for grades K-8. www.coreknowledge.org

Freire, P (1970) Pedagogy of the oppressed. London: Continuum

Gibb, N (2015) How E D Hirsch came to shape UK Government policy. In Simons, J and Porter, N (eds)

Knowledge and the curriculum: A collection of essays to accompany E D Hirsch's lecture at Policy Exchange. London: Policy Exchange.

Gutstein, E (2012) Using critical mathematics to understand the conditions of our lives: United States. In T Wrigley, P Thomson and B Lingard (eds) Changing schools: Alternative ways to make a world of difference. London: Routledge

Hundred Academics (2013) Open letter 'Too much too young'. The Independent, 19 March.

http://www.independent.co.uk/voices/letters/letters-gove-will-bury-pupils-in-facts-and-rules-8540741.html

Labour Party (2018) Towards a National Education Service.

https://www.scribd.com/document/374043317/Towards-a-NES

Marx, K (1894) Capital, vol III. www.marxists.org/archive/marx/works/1894-c3/ch48.htm (accessed 26 May 2017)

Medway, P and Kingwell, P (2010) A curriculum in its place: English teaching in one school 1946-1963.

History of Education 39(6), 749-65

More Than A Score (2017) Beyond the exam factory: alternatives to high-stakes testing. London: More Than A Score

Noddings, N (2006) Critical lessons: What our schools should teach. Cambridge: Cambridge University Press

Ofsted (2017) Bold beginnings: the Reception curriculum in a sample of good and outstanding primary schools (Nov 2017, no. 170045).

Roberts, M (2014) Powerful knowledge and geographical education. The Curriculum Journal 25(2): 187-209

Rosen, H (1981) Neither Bleak House nor Liberty Hall: English in the curriculum. In J Richmond (ed)

(2017) Harold Rosen: Writings on life, language and learning 1958-2008. London: UCL IOE Press

Rosen, M (2012) Dear Mr Gove. Marxism conference, London, July 2012. 
http://swpradiocast.bandcamp.com/track/dear-mr-gove-marxism-2012

Ryle, G (1949) The concept of mind. Harmondsworth: Penguin.

Schama, S (2013) Speech at Hay Festival 2013.

http://www.hayfestival.com/p-6108-simon-schama-and-teachers.aspx

Tebbit, N (1985), cited in Graddol, D et al (eds) (1991) Talk and learning 5-16: an inservice pack on oracy for teachers. Milton Keynes: Open Universitiy Press, p52

Thatcher, M (1987) Speech to Conservative Party conference.

http://www.margaretthatcher.org/document/106941

Wellcome Trust (2016) Written evidence (PRI0378) to House of Commons Education Committee (2017)

Primary Assessment (footnote 60).

https://publications.parliament.uk/pa/cm201617/cmselect/cmeduc/682/682.pdf

Williams, R (1961) The long revolution. London: Chatto and Windus

Williams, R (1985) The country and the city. London: Hogarth.

Wrigley, T, Thomson, P and Lingard, B (2012) Resources for changing schools: ideas in and for practice. In $\mathrm{T}$ Wrigley, $\mathrm{P}$ Thomson and B Lingard (eds) Changing schools: alternative ways to make a world of difference. London: Routledge

Wrigley, T (2014) The politics of curriculum in schools. London: Centre for Labour and Social Studies (CLASS) http://classonline.org.uk/pubs/item/the-politics-of-curriculum-in-schools

Young, M (2010) Why educators must differentiate knowledge from experience. Pacific-Asian Education, 22(1), pp9-20

Young, M and Lambert, D with Roberts, C and Roberts, M (2014) Knowledge and the future school:

Curriculum and social justice. London: Bloomsbury 